\title{
Comparing neuromodulation modalities involving the suprascapular nerve in chronic refractory shoulder pain: retrospective case series and literature review
}

\author{
Saugat Dey \\ Center for Pain and Spine, Dartmouth-Hitchcock Medical Center, Lebanon, NH, USA
}

\begin{abstract}
Chronic shoulder pain not relieved by either conservative or surgical management is referred to as chronic refractory shoulder pain. This is a retrospective case series where chronic refractory shoulder pain patients were treated either with peripheral nerve stimulation (PNS) or with pulsed radiofrequency ( $\mathrm{p}-\mathrm{RF}$ ) therapy to the suprascapular nerve. Both patients receiving PNS reported $100 \%$ pain relief for the first month. At the 3- and 6-month follow-ups, one patient continued to experience 100\% relief while the other reported $90 \%$ relief. One patient undergoing p-RF experienced about 90\% pain relief at both 1- and 3-month intervals and 0\% relief at the 6-month interval. The other patient with p-RF experienced $33 \%$ relief at 1 -month and $0 \%$ relief thereafter. No patient reported any complications. The results of previous randomized controlled trials evaluating the efficacy of $\mathrm{p}-\mathrm{RF}$ administered to the suprascapular nerve were mixed, and there is a lack of published studies on PNS effects. Neuromodulation of the suprascapular nerve can be effective for chronic refractory shoulder pain patients. Larger scale randomized controlled trials comparing PNS and p-RF are needed to better understand their respective therapeutic capacity.
\end{abstract}

Keywords: Shoulder pain; Neuromodulation therapy; Suprascapular Nerve; Pulsed radiofrequency treatment; Peripheral nerve stimulation

Shoulder pain is a common musculoskeletal pain problem. Pain in the shoulder region that persists for 6 months or more has been defined as chronic shoulder pain [1]. The commonest etiologies associated with chronic shoulder pain are rotator cuff muscle disorders, and acromioclavicular joint and glenohumeral joint pathologies [2]. Chronic shoulder pain that does not respond to either conservative management (oral anti-inflammatory medications, physical therapy, and targeted steroid or local anesthetic injections) or to surgical interventions is referred to as chronic refractory shoulder pain. Neuromodulation, with either a peripheral nerve stimulator (PNS) or with pulsed radiofrequency ( $\mathrm{p}$ -
$\mathrm{RF}$ ), remain the only viable therapeutic options for such patients.

\section{CASE REPROT}

This is a retrospective case series and approval was obtained from the Institutional Review Board of Benefis Health System (IRB No. 041720). Informed consent was waived due to the retrospective nature of the study. All patients having shoulder pain for more than 6 months, who had previously failed both conservative management and surgical treatment and who had subsequently been treated with neuromodulation of the suprascapular

Received: January 19, $2021 \quad$ Revised: February 10, $2021 \quad$ Accepted: February 13, 2021

Correspondence to: Saugat Dey

Center for Pain and Spine, Dartmouth-Hitchcock Medical Center, 7 Timberwood Drive, Apt 230, Lebanon, NH 03766, USA

Tel: +1-267-736-0286, Fax: +1-6036506322, E-mail: saugatharidwar@gmail.com, ORCID: https://orcid.org/0000-0003-4128-3337

\section{Financial support: None.}

Conflict of interest: None.

Copyright@ 2021 Korean Shoulder and Elbow Society. All Rights Reserved.

This is an Open Access article distributed under the terms of the Creative Commons Attribution Non-Commercial License (http://creativecommons.org/licenses/by-nc/4.0/) which permits unrestricted non-commercial use, distribution, and reproduction in any medium, provided the original work is properly cited. 
nerve by the same pain physician between July 1, 2017 and March 31, 2020, were included in the review. Patients were excluded if they did not follow up with a neuromodulation procedure at 1-, 3-, and 6-month intervals. Patients were also excluded if their Numeric Pain Score or self-reported functional assessment was not available for any of the follow-up visits. Table 1 delineates the process of patient selection for the retrospective case series.

All patients demonstrated $>50 \%$ temporary pain relief with ultrasound guided diagnostic suprascapular nerve blocks with 2 $\mathrm{mL}$ of $0.25 \%$ bupivacaine and $40 \mathrm{mg}$ of triamcinolone prior to their neuromodulation procedures. The neuromodulation procedures were performed using ultrasound guidance under aseptic precautions. The patients were placed in a prone position and a linear transducer was placed oblique to the scapular spine. The hyperechoic suprascapular nerve was localized in the supraspinous fossa. The nerve was accessed using a lateral to medial inplane approach. Nerve position was acquired using confirmation of optimal sensory and motor stimulation via demonstration of paresthesia over the shoulder area and contractions in the supraspinatus muscles, respectively.

All patients who were treated with neuromodulation first underwent a psychological screening to rule out any uncontrolled mental health or substance use problems as well as unrealistic treatment expectations. Patients treated with PNS were implanted with the Bioness Stimrouter (Bioness Inc., Valencia, CA, USA) lead using local anesthetic and light sedation as needed. An external pulse generator was used to power and regulate the lead, and it was affixed to the skin overlying the receiver end of the lead. For patients treated with p-RF, after using local anesthetic, a $20-$ G $100-\mathrm{mm}$ curved tip radiofrequency cannula with a $10-\mathrm{mm}$ active tip (Avanos Medical, Alpharetta, GA, USA) was used to perform two sets of treatments for 120 seconds each at a frequency of $2 \mathrm{~Hz}$ and a pulse width of $20 \mathrm{~ms}$ at $42^{\circ} \mathrm{C}$.

\section{Case 1}

A 65-year-old female presented with gradually worsening left shoulder pain which started insidiously 5 years ago. The patient was under the care of orthopedics specialists and magnetic resonance imaging (MRI) of the shoulder revealed a torn rotator cuff with degenerative joint disease of the glenohumeral and acromioclavicular joints. Her pain had failed to respond to oral nonsteroidal anti-inflammatory drugs (NSAIDs) and physical therapy. Rotator cuff repair with distal clavicle resection was performed but was not beneficial. Pain relief was also not obtained after a glenohumeral joint steroid injection. After evaluation in the pain clinic and a left suprascapular nerve diagnostic block, she underwent a PNS implant. Her baseline pain score was $7 / 10$ and she was painless, i.e., pain score $0 / 10$, at the 1-, 3- and 6-month follow-up visits. The patient also reported an $80 \%$ improvement in function at 1-month and $70 \%$ improvement at the 3 -month and 6-month visits.

\section{Case 2}

A 45-year-old female presented with right shoulder pain which started after lifting a heavy load 2 years ago. She underwent conservative treatments including NSAIDs, physical therapy, and aquatic therapy which provided minimal pain relief. An MRI of the shoulder demonstrated a rotator cuff tear with acromioclavicular joint hypertrophy. The patient was evaluated by orthopedics specialists as a poor surgical candidate due to her history of obesity and diabetes. The patient was referred to the pain clinic,

Table 1. The process of selecting patients for the retrospective case series

Inclusion criteria (must qualify every criterion to be included)

- Patient aged above 18 years

- Patient was seen by author at the pain clinic.

- Patient was experiencing shoulder pain for more than 6 months.

- Patient's shoulder pain didn't improve with conservative management.

- Patient's shoulder pain didn't improve with surgical interventions or patient wasn't considered a surgical candidate.

- Patients had $>50 \%$ temporary pain relief with ultrasound guided diagnostic suprascapular nerve blocks prior to their neuromodulation procedures.

- Patient was treated with either pulsed radiofrequency therapy or peripheral nerve stimulation implant of suprascapular nerve by author.

- Patient had followed up visits with author post neuromodulation procedure at 1-, 3-, and 6-month intervals. Exclusion criteria (will be excluded if meets any criteria)

\footnotetext{
- Patient had neuromodulation of multiple nerves, i.e., both suprascapular nerve and axillary nerve.

- Patient had at least one missing Numeric Pain Score and/or a self-reported functional assessment score for the post procedural follow-up visits.
} 
and a right acromioclavicular joint steroid injection was initially performed which was not beneficial. Due to some clinical concern for subacromial bursitis, an ultrasound guided subacromial bursa injection was subsequently performed which provided only a few days of pain relief. At this point, right suprascapular nerve block was performed which was diagnostic and the patient elected to proceed with a $\mathrm{p}-\mathrm{RF}$ treatment. The patient's pre-neuromodulation pain score was $9 / 10$ and it improved to $1 / 10$ at 1 and 3-month follow-up visits. However, the pain returned to the baseline score of $9 / 10$ at the 6-month follow-up. The patient reported a $60 \%$ improvement in function at 1-month, $25 \%$ improvement at 3 -months, and a return to baseline ( $0 \%$ improvement) at the 6-month visit.

\section{Case 3}

A 52-year-old female presented with insidious onset and gradually worsening left shoulder pain for the last 9 years. The patient was diagnosed with adhesive capsulitis. Physical therapy was not beneficial. She underwent left shoulder capsular release and subacromial bursectomy which provided pain relief for only 1 month. Repeat shoulder MRI only showed post-surgical changes and no further surgeries were recommended by orthopedics specialists. The patient was on oral opioid therapy for a few years which was not beneficial and was subsequently tapered off. Patient was seen in the pain clinic and after a diagnostic left suprascapular nerve block, she decided to proceed with a PNS implant. Post PNS, her pain score improved from baseline $10 / 10$ to $0 / 10$ at 1-month, and to $1 / 10$ at both 3- and 6-month follow-up visits. Her self-reported functional improvement was $75 \%$ at 1-month, $70 \%$ at 3 -month, and $60 \%$ at the 6 -month visit.

\section{Case 4}

A 40-year-old female presented with non-traumatic right shoulder pain which started 20 years ago and worsened recently. Physical therapy and oral NSAIDs were somewhat beneficial. An MRI of the shoulder showed subacromial bursitis. A subacromial bursa injection under ultrasound provided only a few weeks of pain relief. She was evaluated by orthopedics specialists and no surgeries were recommended. Right suprascapular nerve block was diagnostic and the patient opted to proceed with p-RF treatments. the patient experienced improvement in pain scores from 6/10 pre-procedure to $4 / 10$ at 1-month with return to baseline pain at 3-month and 6-month follow-up visits. Self-reported percentage improvement in function was $20 \%$ at 1 month with no improvement subsequently.

Table 2 delineates the clinical summary of all patients. No patient reported any immediate or late complications. However,

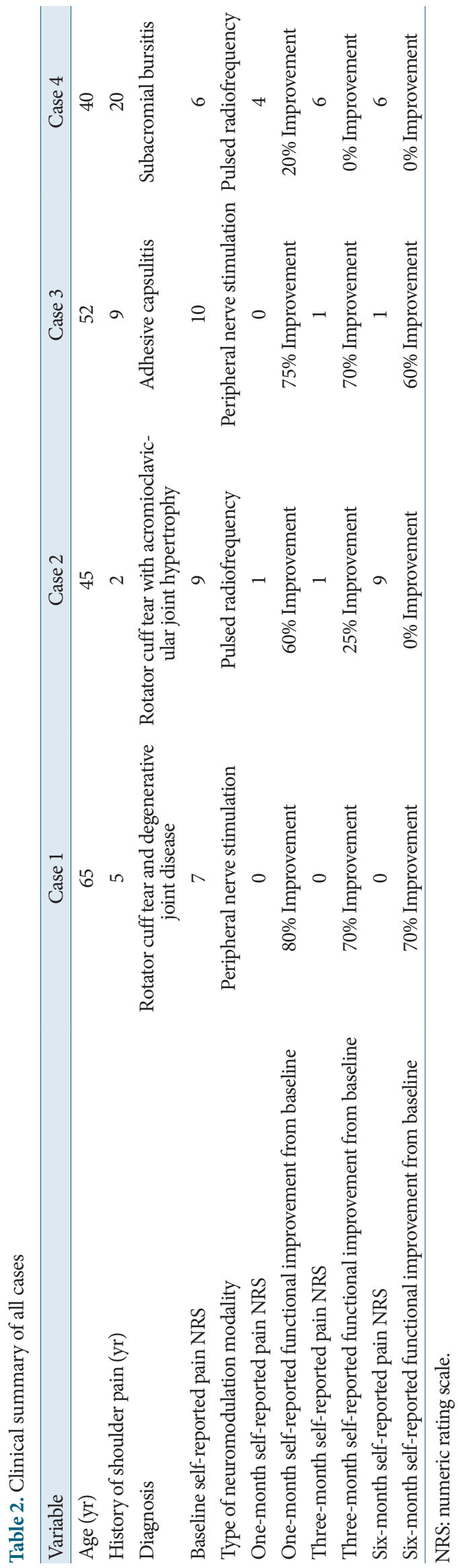

https://doi.org/10.5397/cise.2021.00038 
both patients treated with PNS (cases 1 and 3) reported the need for frequent charging of the external pulse generator which resulted in some interruption of their treatment.

\section{Literature Review}

After searching Medline and Google Scholar databases, six randomized controlled trials (RCT) on p-RF therapy involving the suprascapular nerve were found and are summarized in Table 3 [3-8]. Most patients in these studies noted improvement in pain, disability scores, and shoulder joint range of motion from their baseline to post p-RF therapy. However, when we analyzed the superiority of $\mathrm{p}$-RF over other comparative modalities for improvement in chronic shoulder pain, the results were mixed. P-RF was statistically superior to intra-articular steroid injection [3], physical therapy alone [6], and lidocaine only [8] nerve block for a maximum duration of 12 weeks or 3 months. However, p-RF was not significantly superior to transcutaneous electrical nerve stimulation at 12 weeks [4], lidocaine only nerve block at 6 months [5], or photobiomodulation therapy at 6 months [7].

There were no RCTs found that assessed the efficacy of PNS therapy to the suprascapular nerve in chronic refractory shoulder pain patients. Table 4 lists all four clinical reports obtained for stimulator implants on the suprascapular nerve [9-12]. Among the two case reports listed: one patient had no pain at rest and excellent shoulder joint range of motion at the 3-month follow-up [9], while the other had no pain and did not require any pain medications at 9 months post-implantation [11]. There was also a large prospective case series which included one patient who underwent an implant on the suprascapular nerve and experienced $66.7 \%$ improvement in pain scores and $80 \%$ improvement in movement capacity [12]. Lastly, there was a retrospective case series in which a subset of nine patients underwent suprascapular nerve stimulator implant: pain score improved $>50 \%$ for eight patients, mean pain improvement was $70 \%$, and 6 patients had $>50 \%$ improvement at last follow-up which was between 2 to 4 years [10].

\section{DISCUSSION}

In this case series, the suprascapular nerve was the target of neuromodulation over the axillary nerve as the suprascapular nerve comprises $70 \%$ of sensory supply to the shoulder joint, the capsule, and the overlying skin as well as providing motor innervation to two of the rotator cuff muscles [13]. The analgesic action

Table 3. Summary of published randomized controlled trials on p-RF therapy of suprascapular nerve

\begin{tabular}{|c|c|c|c|c|}
\hline $\begin{array}{l}\text { First author } \\
\text { (year of publication) }\end{array}$ & Group & Follow-up & Outcome measure & Result \\
\hline Eyigor (2010) [3] & $\begin{array}{l}\text { a. } p-R F, n=25 \\
\text { b. Intra-articular } \\
\text { corticosteroid, } n=25\end{array}$ & $12 \mathrm{wk}$ & $\begin{array}{l}\text { VAS, ROM, SPADI, } \\
\text { short-form 36, Beck } \\
\text { depression scale question- } \\
\text { naires }\end{array}$ & $\begin{array}{l}\text { p-RF group had significant improvement in VAS } \\
\text { at rest at weeks } 1 \text { and } 4, \text { VAS at movement at } \\
\text { week } 1 \text {, and VAS at night at weeks } 1,4 \text {, and } 12 \text {. } \\
\text { p-RF group had significant improvement in } \\
\text { SPADI at weeks } 1,4 \text {, and } 12 \text {. } \\
\text { p-RF group had significant improvement in active } \\
\text { and passive abduction at weeks } 1 \text { and } 4 \text {. }\end{array}$ \\
\hline Korkmaz (2010) [4] & $\begin{array}{l}\text { a. } p-R F, n=20 \\
\text { b. Transcutaneous electrical } \\
\text { nerve stimulation, } n=20\end{array}$ & $12 \mathrm{wk}$ & $\begin{array}{l}\text { VAS, ROM, SPADI, } \\
\text { short-form } 36\end{array}$ & $\begin{array}{l}\text { p-RF group had significant improvement in } \\
\text { SPADI at week } 1 .\end{array}$ \\
\hline Gofeld (2013) [5] & $\begin{array}{l}\text { a. } p-R F, n=12 \\
\text { b. Nerve block with } \\
\text { lidocaine, } n=10\end{array}$ & $6 \mathrm{mo}$ & NRS, LSI, SPADI, CMS & $\begin{array}{l}\text { No significant difference between both groups for } \\
\text { NRS, SPADI, and CMS } \\
\text { p-RF group had significant improvement in LSI at } \\
\text { months } 1 \text { and } 3 \text {. }\end{array}$ \\
\hline Wu (2014) [6] & $\begin{array}{l}\text { a. } \mathrm{p}-\mathrm{RF}+12 \text {-week PT, } \mathrm{n}=21 \\
\text { b. } 12 \text {-week PT, } \mathrm{n}=21\end{array}$ & $12 \mathrm{wk}$ & VAS, ROM, SPADI & $\begin{array}{l}\text { p-RF group had significant improvement in VAS } \\
\text { score, SPADI score, and passive ROM at weeks } \\
1,4,8 \text {, and } 12 \text {. }\end{array}$ \\
\hline Ökmen (2017) [7] & $\begin{array}{l}\text { a. } p-R F, n=30 \\
\text { b. Photobiomodulation } \\
\text { therapy, } n=29\end{array}$ & $6 \mathrm{mo}$ & $\begin{array}{l}\text { VAS, SPADI, Nottingham } \\
\text { Health Profile score }\end{array}$ & $\begin{array}{l}\text { No significant difference between both groups for } \\
\text { any outcome measure }\end{array}$ \\
\hline Alanbay (2020) [8] & $\begin{array}{l}\text { a. } p-R F, n=15 \\
\text { b. Nerve block with } \\
\text { lidocaine, } n=15\end{array}$ & $3 \mathrm{mo}$ & $\begin{array}{l}\text { VAS, ROM, GAS during } \\
\text { upper-body dressing }\end{array}$ & $\begin{array}{l}\text { p-RF group had significant improvement in VAS } \\
\text { score and ROM at months } 1 \text { and } 3 . \\
\text { p-RF group had significant improvement in GAS } \\
\text { at month } 3 \text {. }\end{array}$ \\
\hline
\end{tabular}

p-RF: pulsed radiofrequency, VAS: visual analog scale, ROM: range of motion, SPADI: Shoulder Pain Disability index score, NRS: numeric rating scale, LSI: Likert scale index, CMS: Constant-Murley Score, PT: physical therapy, GAS: Goal Attainment Scale. 
Table 4. Summary of published clinical reports and studies on peripheral nerve implant of suprascapular nerve

\begin{tabular}{|c|c|c|c|c|}
\hline $\begin{array}{l}\text { First author } \\
\text { (year of publication) }\end{array}$ & $\begin{array}{l}\text { Type of study, number of } \\
\text { participants }\end{array}$ & Follow-up & Outcome measure & Result \\
\hline Elahi (2014) [9] & Case report, 1 & $3 \mathrm{mo}$ & Pain score, range of motion & $\begin{array}{l}\text { Patient had no pain at rest and had excellent } \\
\text { range of motion. }\end{array}$ \\
\hline Bouche (2017) [10] & $\begin{array}{l}\text { Retrospective case series, } 9 \\
\text { patients with suprascapular } \\
\text { implant }\end{array}$ & $\begin{array}{l}\text { Mean, } 33.6 \mathrm{mo} \\
\text { median, } 27 \mathrm{mo}\end{array}$ & $\begin{array}{l}\text { Quantitative improvement } \\
\text { in pain }\end{array}$ & $\begin{array}{l}\text { Mean pain improvement was } 70 \% \text {. At last } \\
\text { follow-up, } 6 \text { patients had }>50 \% \text { pain } \\
\text { improvement. }\end{array}$ \\
\hline Kurt (2016) [11] & Case report, 1 & $9 \mathrm{mo}$ & $\begin{array}{l}\text { Pain score, requirement of } \\
\text { pain medications }\end{array}$ & $\begin{array}{l}\text { Patient had no pain and had no requirement } \\
\text { to take pain medications. }\end{array}$ \\
\hline Oswald (2019) [12] & $\begin{array}{l}\text { Prospective case series, } \\
1 \text { patient with suprascapular } \\
\text { implant }\end{array}$ & $3-6 \mathrm{mo}$ & $\begin{array}{l}\text { VAS pain score, activity, opi- } \\
\text { oid consumption }\end{array}$ & $\begin{array}{l}\text { Patient had } 66.7 \% \text { improvement in VAS, } \\
80 \% \text { improvement in activity, and no } \\
\text { change in opioid consumption. }\end{array}$ \\
\hline
\end{tabular}

VAS: visual analog scale.

of PNS therapy is multi-modal and acts both via peripheral and central analgesic mechanisms including modulating inflammatory pathways, the autonomic nervous system, the endogenous pain inhibition pathways, with the involvement of cortical and subcortical areas [14]. p-RF therapy, which involves delivering rapid bursts of electromagnetic fields to the target, is known to enhance the descending pain inhibitory pathways [15].

In our retrospective case series, all patients had both neuromodulation interventions as well as pre-procedural diagnostic nerve blocks performed under ultrasound guidance. Ultrasound was chosen over fluoroscopy guidance as it provides direct real-time nerve visualization, more rapid onset of analgesia, better precision, involves limited trauma, and also reduces radiation exposure [16]. To avoid interoperator variability that might confound the comparison of results, neuromodulation procedures were performed by a single pain practitioner. Also, only patients with complete data for all three 1-, 3-, and 6-month follow-up windows were included in the case review.

A comparison between the two neuromodulation therapy techniques showed the two patients undergoing PNS therapy had better outcomes than the two patients with p-RF therapy, in terms of both numeric pain rating and functional improvement-especially at the 6-month interval. However, this study's sample size is too small to establish any clinically significant superiority for either therapy.

This study is a retrospective case report and hence the evidence obtained is less robust compared to that obtained with a prospective trial. Also, the small sample size and lack of racial or sex diversity in the sample makes generalization of the study results to the general population difficult. The follow-up period was limited to 6 months, therefore assumptions about the longer term effectiveness of the neuromodulation techniques cannot be made.

Peripheral nerve implant to the suprascapular nerve as well as
p-RF therapy of the nerve can both be effective therapeutic options for chronic refractory shoulder pain patients. This study reveals that PNS implants may be effective longer-term than p-RF treatment which tends to significantly lose its therapeutic effect post the 3-month follow-up interval. However, the small sample size and retrospective nature of this study makes it difficult to reach any definitive conclusions about the superiority of either of these therapies. Thus, we need larger RCTs to compare these two neuromodulation modalities involving the suprascapular nerve in order to build a robust treatment plan for chronic refractory shoulder pain patients.

\section{ORCID}

Saugat Dey https://orcid.org/0000-0003-4128-3337

\section{REFERENCES}

1. Burbank KM, Stevenson JH, Czarnecki GR, Dorfman J. Chronic shoulder pain: part I. Evaluation and diagnosis. Am Fam Physician 2008;77:453-60.

2. Mitchell C, Adebajo A, Hay E, Carr A. Shoulder pain: diagnosis and management in primary care. BMJ 2005;331:1124-8.

3. Eyigor C, Eyigor S, Korkmaz OK, Uyar M. Intra-articular corticosteroid injections versus pulsed radiofrequency in painful shoulder: a prospective, randomized, single-blinded study. Clin J Pain 2010;26:386-92.

4. Korkmaz OK, Capaci K, Eyigor C, Eyigor S. Pulsed radiofrequency versus conventional transcutaneous electrical nerve stimulation in painful shoulder: a prospective, randomized study. Clin Rehabil 2010;24:1000-8.

5. Gofeld M, Restrepo-Garces CE, Theodore BR, Faclier G. Pulsed radiofrequency of suprascapular nerve for chronic shoulder pain: a randomized double-blind active placebo-controlled 
study. Pain Pract 2013;13:96-103.

6. Wu YT, Ho CW, Chen YL, Li TY, Lee KC, Chen LC. Ultrasound-guided pulsed radiofrequency stimulation of the suprascapular nerve for adhesive capsulitis: a prospective, randomized, controlled trial. Anesth Analg 2014;119:686-92.

7. Ökmen BM, Ökmen K. Comparison of photobiomodulation therapy and suprascapular nerve-pulsed radiofrequency in chronic shoulder pain: a randomized controlled, single-blind, clinical trial. Lasers Med Sci 2017;32:1719-26.

8. Alanbay E, Aras B, Kesikburun S, Kizilirmak S, Yasar E, Tan AK. Effectiveness of suprascapular nerve pulsed radiofrequency treatment for hemiplegic shoulder pain: a randomized-controlled trial. Pain Physician 2020;23:245-52.

9. Elahi F, Reddy CG. Neuromodulation of the suprascapular nerve. Pain Physician 2014;17:E769-73.

10. Bouche B, Manfiotto M, Rigoard P, et al. Peripheral nerve stimulation of brachial plexus nerve roots and supra-scapular nerve for chronic refractory europathic pain of the upper limb. Neuromodulation 2017;20:684-9.

11. Kurt E, van Eijk T, Henssen D, Arnts I, Steegers M. Neuromodu- lation of the suprascapular nerve. Pain Physician 2016;19:E2359.

12. Oswald J, Shahi V, Chakravarthy KV. Prospective case series on the use of peripheral nerve stimulation for focal mononeuropathy treatment. Pain Manag 2019;9:551-8.

13. Tran J, Peng PW, Agur AM. Anatomical study of the innervation of glenohumeral and acromioclavicular joint capsules: implications for image-guided intervention. Reg Anesth Pain Med 2019;44:452-8

14. Lin T, Gargya A, Singh H, Sivanesan E, Gulati A. Mechanism of peripheral nerve stimulation in chronic pain. Pain Med 2020; 21(Suppl 1):S6-12.

15. Hagiwara S, Iwasaka H, Takeshima N, Noguchi T. Mechanisms of analgesic action of pulsed radiofrequency on adjuvant-induced pain in the rat: roles of descending adrenergic and serotonergic systems. Eur J Pain 2009;13:249-52.

16. Sites BD, Brull R. Ultrasound guidance in peripheral regional anesthesia: philosophy, evidence-based medicine, and techniques. Curr Opin Anaesthesiol 2006;19:630-9. 